\title{
Grigorenko YN, Chilingar GV, Sobolev VS, Andiyeva TA, and Zhukova LI: Petroleum Accumulation Zones on Continental Margins
}

\author{
Lee C. Gerhard
}

(C) Springer-Verlag Berlin Heidelberg 2013

2012 | John Wiley \& Sons, Scrivener Publishing LLC | 448 pp | Hardback EUR 169.00 | USD 195.00 | ISBN 978-1-118-38507-4

The strength of this book is in its summation of continental margin oil and gas discoveries and production of the world. It cuts no new scientific ground, but appears to lay the basis for recommendations for Russian exploration of its marginal waters.

The first two chapters are discussions of the habitat of continental shelf oil fields and the sedimentologic characteristics of the reservoir rocks, generally categorized. The language is convoluted and complex, probably owing to difficulties in translation to English.

Chapters three and four are valuable synopses of Pacific Group continental margin hydrocarbon accumulations and Atlantic Group continental margins, the differences largely due to tectonic convergence versus passive behavior.

These synopses form the meat of the book, encompassing all of the known continental margin hydrocarbon deposits.
Such summaries are valuable tools for the practitioner who has widespread interest in identifying analogs for new plays. Of the book's 400 plus pages, 350 are concerned with the synopses-a trove of global information.

The ultimate goal of the book appears to be a forecast of hydrocarbon accumulations on Russian continental shelves, which is the last technical chapter of the book, based on analysis of similar accumulations around the world in the preceding chapters.

The book concludes with a list of literature citations. Practitioners will find this book a handy reference to gain low-level insight into any of the global continental shelf oil and gas basins, but it may be most valuable to those working in the management of small to intermediate energy and petroleum companies considering new areas to explore. The technical level is appropriate for managers who are not employed as geoscientists but are familiar with principles of exploration geology. The book, Petroleum Accumulation Zones on Continental Margins, will be particularly interesting to those with business interests in Russia.
L. C. Gerhard ( $\square)$

University of Kansas, Lawrence, KS, USA

e-mail: leeg@sunflower.com 